\title{
Correction to: Infantile fibrosarcoma with TPN3-NTRK3 fusion in a boy with Bloom Syndrome
}

\author{
Sue M. Huson ${ }^{1} \cdot$ Timo Staab $^{2} \cdot$ Marta Pereira $^{1} \cdot$ Heather Ward $^{1} \cdot$ Roberto Paredes $^{3} \cdot$ D. Gareth Evans ${ }^{1}$. \\ Daniel Baumhoer ${ }^{4} \cdot$ James O'Sullivan ${ }^{1} \cdot$ Ed Cheesman $^{5} \cdot$ Detlev Schindler $^{2} \cdot$ Stefan Meyer ${ }^{3,6,7}$ (1)
}

Published online: 6 January 2021

(c) The Author(s) 2021

\section{Correction to: Familial Cancer https://doi.org/10.1007/s10689-020-00221-1}

In the original article it was not clear that the senior authorship of this report is shared by D Schindler and S Meyer, reflecting the contributions made. The senior authorship should now be recognised as being shared.

Publisher's Note Springer Nature remains neutral with regard to jurisdictional claims in published maps and institutional affiliations.

Detlev Schindler and Stefan Meyer have shared senior authorship.

The original article can be found online at https://doi.org/10.1007/ s10689-020-00221-1.

Stefan Meyer

stefan.meyer@manchester.ac.uk

1 Department of Genetic Medicine, St Mary's Hospital, Central Manchester Foundation Trust, Manchester, UK

2 Department of Human Genetics, University of Würzburg, Würzburg, Germany

3 Stem Cell and Leukaemia Proteomics Laboratory, School of Cancer and Imaging Sciences, The University of Manchester, Manchester Academic Health Science Centre, Manchester, UK

4 Institute for Medical Genetics and Pathology, University Hospital Basel, Basel, Switzerland
5 Department of Paediatric Histopathology, Royal Manchester Children's Hospital, Central Manchester Foundation Trust, Manchester, UK

6 Departments of Paediatric Haematology Oncology, Royal Manchester Children's Hospital, Central Manchester Foundation Trust, Manchester, UK

7 Academic Unit of Paediatric and Adolescent Oncology, University of Manchester, c/o Young Oncology Unit, The Christie NHS Foundation Trust, Wilmslow Road, Manchester M20 6XB, UK 